\title{
Actin reorganization is involved in vasoactive intestinal peptide induced human mast cells priming to fraktalkine-induced chemotaxis
}

\author{
Amr E El-Shazly \\ Department of Oto-Rhino-Laryngology \\ and Head and Neck Surgery, Liege \\ University Hospital (Centre hospitalier \\ Universaitaire-C.H.U.), Liege, Belgium
}

\begin{abstract}
We recently reported a novel neuro-immuno co-operation between vasoactive intestinal peptide (VIP) and fraktalkine (FKN) in recruiting human mast cells to the asthmatic airway that provided a classical example of priming effect on mast cells migratory function, but the role of the F-actin in human mast cell chemotaxis' priming is poorly defined. Therefore the aim of this study was to further investigate the biophysical role of the cytoskeletal element; the F-actin, intracellular reorganization and its polymerization in mast cell priming of chemotaxis function. In the present communication it is shown by immunofluoresence confocal microscopy analysis that physical F-actin intracellular reorganization in a membrane bound manner on human mast cell is involved in VIP-induced priming of human mast cell chemotaxis against FKN. The F-actin reorganization was calcium independent and without modification of its contents as assessed by fluorescence-activated cell scanning analysis. These results identify a novel role for the biophysical association of F-actin in the crosstalk between neuro-inflammatory mediators and mast cells and may be an important target for therapeutic modalities in allergic inflammation.
\end{abstract}

Keywords: mast cells, chemotaxis, neuroimmuno-axis, F-actin intracellular reorganization, VIP, priming

\section{Introduction}

Human airway smooth muscle cells (HASMC) play a significant role in recruiting mast cells to the asthmatic bronchi (Brightling et al 2005; Sutcliffe et al 2006). The contribution of fraktalkine (FKN), the CX3C chemokine produced by HASMC to mast cell chemotaxis, needed the cooperation of the neuropeptide vasoactive intestinal peptide (VIP), without altering FceR1 or CD117 expression on mast cells (El-Shazly et al 2006). Similar synergistic cooperation between stem cell factor and tumor necrosis factor- $\alpha$ on intercellular adhesion molecule-1 expression on human mast cells was demonstrated, which further provide insight for cross-talk between different signaling pathways that can help in recruiting mast cells to the allergic inflammatory site (Tsang et al 2005).

Chemotaxis primer is an agent that will not induce chemotaxis when it reacts with its specific receptor on the cell surface, but will put the cell in the ready-to-go position to re-stimulation and will do so even with a suboptimal dose of the proper chemokine that attracts the cell type. This scenario of crosstalk between mediators and inflammatory cells is applicable to the pathophysiology of allergic rhinitis and asthma where there is a pool of allergic mediators at different concentrations involved in the allergic site.

The literature review is rich in the different signal transduction pathways and the different protein kinases involved in mast cell chemotaxis. However, apart from 
its well acknowledged cytoskeletal shape changes, little is known about the role played by the F-actin in the signal transduction of mast cell chemotaxis (Jackson et al 2005; Samayawardhena et al 2006; Rivera et al 2007; Kim et al 2007; Samayawardhena et al 2007).

Accordingly, the current study was designed to look into the role of F-actin in the signal transduction of priming mast cell chemotaxis function. Our recently reported novel clinical crosstalk model of the neuro-immuno-inflamatory axis in recruiting mast cells to the airway; FKN-VIP-mast cells (El-Shazly et al 2006) were adopted for the following biophysical assay.

\section{Materials and methods}

\section{Cell cultures}

Human mast cell line (HMC-1) (Butterfield et al 1988) was cultured in 10\% fetal calf serum/Dubecco's modified Eagle's Medium and was passaged every 3-5 days with trypsinethylenediaminetetraacetic acid (EDTA) (Invitrogen Life Technologies, Carlsbad, CA).

\section{Chemotaxis assay}

Chemotactic experiments were performed in 48-well microchemotaxis chambers as described elsewhere (Berger et al 2001). As for chemotaxis assay of primed HMC-1, cells were first incubated with $1 \mu \mathrm{M}$ VIP for 30 minutes (Sigma-Aldrich, St. Louis, MO), washed twice and resuspended in the culture media before inducing their chemotaxis response against $10 \mathrm{ng} / \mathrm{ml} \mathrm{FKN} \mathrm{(R} \mathrm{and} \mathrm{D} \mathrm{Systems,} \mathrm{Minneapolis,} \mathrm{MN).} \mathrm{Mast}$ cells were then counted by microscopy in 5 selected high power fields (magnification $\times 400$ ). Results of the chemotaxis experiments were expressed as mast cells $/ 5$ high power fields (5hpf).

\section{Microspectrofluorimetry}

Changes in HMC-1 intracellular calcium concentration were assessed using the $\mathrm{Ca}^{2+}$-sensitive probe indo-1 (calbiochem) precisely as previously described (Bonnet et al 2003). $10 \mu \mathrm{M}$ ATP was used as positive control that demonstrated the ability of HMC-1 to mobilize intracellular calcium. $1 \mu \mathrm{M}$ VIP, $10 \mathrm{ng} / \mathrm{ml} \mathrm{FKN}$, and $1 \mu \mathrm{M} \mathrm{VIP}+10 \mathrm{ng} / \mathrm{ml} \mathrm{FKN}$ ability to mobilize intracellular calcium were tested in similar fashion.

\section{Actin reorganization assessment with phalloidin-FITC}

As for actin reorganization and content assessment, after each challenge, HMC-1 were fixed in cold methanol for 20 minutes and permeabilized with $0.1 \%$ saponin
(Sigma-Aldrich) for another 30 minutes. The cells were then stained with phalloidin-fluorescein isothiocyanate (FITC) (Sigma-Aldrich) labeled for 1 hour in the dark, on ice, and analyzed by fluorescence-activated cell scanning (FACS) or confocal microscopy.

\section{Results and discussion}

In the past decade or so, intensive research in the fields of neuropeptides and immune cells has resulted in accumulating evidence that supports the existence of neuroimmune axis (Numa et al 1992; El-Shazly et al 1996, 1997). The 28 amino acid VIP polypeptide, which exists in the parasympathetic nerves, and to a lesser extent in the sensory fibers, is one of the most abundant of the neuropeptides found in the upper and lower airways (Ghatei et al 1982; Baranuik et al 1990). It has been detected in the fluids of hypersensitivity reactions (Mosimann et al 1993). The biological effects of VIP on airway functions include regulation of vascular tone, airway caliber, and mucus secretion (Said 1982; Peatfield et al 1983; Palmer et al 1986; Stjarne et al 1991).

On inflammatory cells, VIP has the potential to modulate T-lymphocyte and human eosinophil chemotaxis (Delgado et al 1995; El-Shazly et al 2000) at wide range of doses. However, VIP at the same wide range doses did not induce human mast cell chemotaxis, but acted as a primer to suboptimal dose of $10 \mathrm{ng} / \mathrm{ml} \mathrm{FKN-induced} \mathrm{mast} \mathrm{cell} \mathrm{chemotaxis} \mathrm{(El-Shazly}$ et al 2006). Nonetheless, little is known about the role of F-actin in mast cell priming of chemotaxis function.

FKN the CX3C chemokine attracts human mast cells in boyden chambers in a classical bell-like shape dosedependent manner with optimal doses of $25-50 \mathrm{ng} / \mathrm{ml}$ through a CX3CR1 receptor stimulation that is linked to PKC epsilon and delta, increase in F-actin contents and rapid shape changes (El-Shazly et al 2006). Herein, it is shown that the low nonstimulatory dose of $10 \mathrm{ng} / \mathrm{ml}$ caused mast cell chemotaxis after the cells have been primed by $1 \mu \mathrm{M}$ VIP that, per se, did not cause chemotaxis (Figure 1a).

Chemokine-mediated signal transduction is believed to involve (i) $\mathrm{Ca}^{2+}$ mobilization, protein kinase $\mathrm{C}$ and heterotrimeric GTP-binding proteins in a classical view (Downey 1994), and (ii) kinases and phosphatases, adaptor proteins, and small GTP-binding proteins in an alternate view (Bokoch 1995; Bacon et al 1996; Kanal et al 1997). Thus, the role of $\mathrm{Ca}^{2+}$ as a second messenger was investigated. Neither FKN nor VIP mobilized intracellular $\mathrm{Ca}^{2+}$ in mast cells. Similar results were obtained after the cells have been primed with VIP (Figure 1b) indicating that the VIP-priming effect was $\mathrm{Ca}^{2+}$-independent. 
(A)

(i)

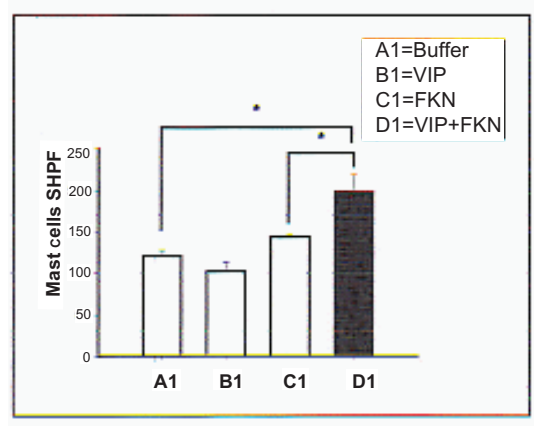

(ii)

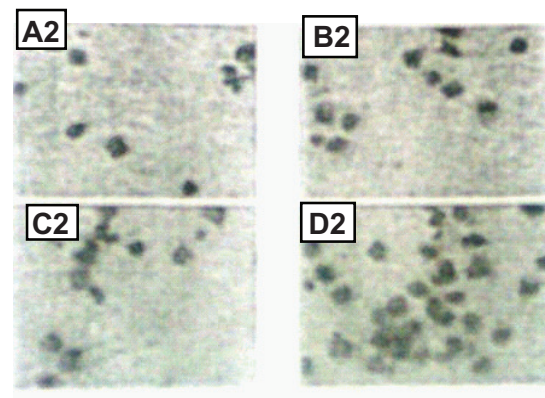

(B)
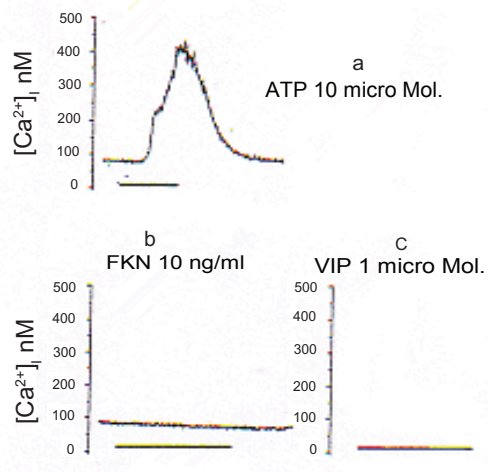

d

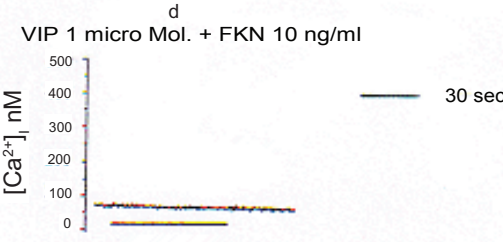

(C)
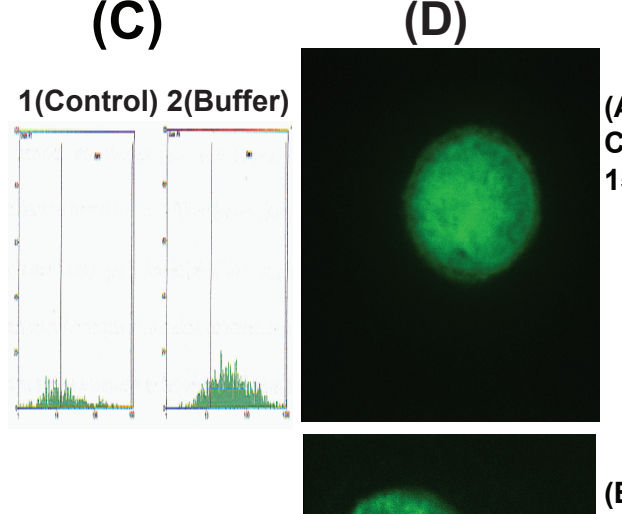

(B)

VIP

15 Min.
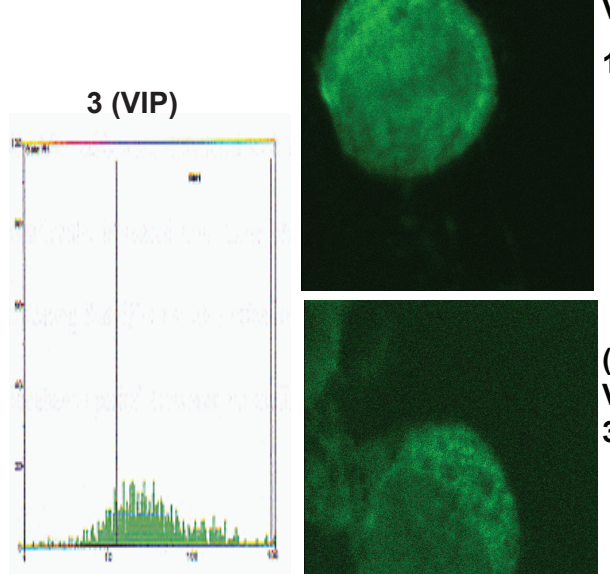

Control

$15 \mathrm{Min}$.

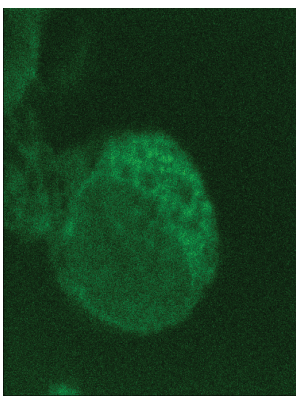

(C)

VIP

30 Min.

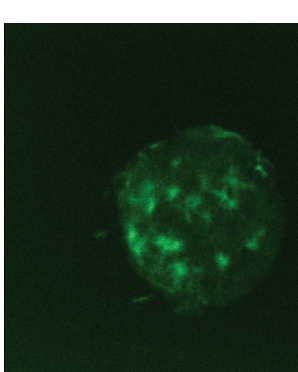

(D)

FKN

15 Min.

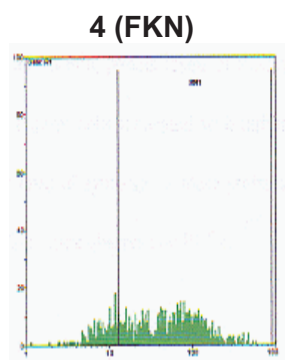

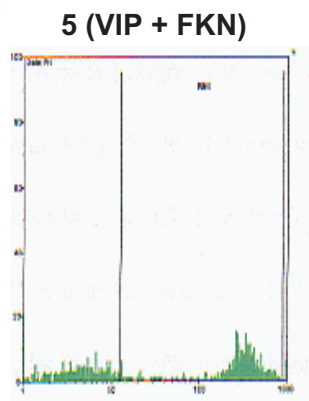

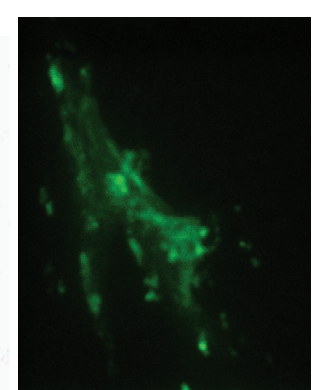

(E)

VIP + FKN

Figure I (a) Priming effect of I $\mu$ MVIP on $10 \mathrm{ng} / \mathrm{ml} \mathrm{FKN-induced} \mathrm{mast} \mathrm{cells} \mathrm{chemotaxis.} \mathrm{Upper} \mathrm{panel} \mathrm{(i,} \mathrm{AI-DI)} \mathrm{demonstrate} \mathrm{the} \mathrm{data} \mathrm{of} \mathrm{the} \mathrm{number} \mathrm{of} \mathrm{mast} \mathrm{cells}$ per 5 selected high power field $(5 \mathrm{hpf} ; \times 400) \pm$ SEM of 6 independent experiments each performed in triplicate. Asterisks indicate $p<0.05$ by paired $t$-test. Lower panel (ii, A2-D2) demonstrates mast cells in I selected HPF as one experiment representative of 6 all showing similar results. (b) Effect of I $\mu M$ ATP, I $\mu M$ VIP, I0 ng/ml FKN, and I $\mu$ MVIP + $10 \mathrm{ng} / \mathrm{ml}$ FKN on mast cells intracellular calcium mobilization. Results are of one representative of 4 independent experiments all showing similar results. Traces are from $27-I 25$ cells. (c) Fluocytometry of F-actin in mast cells. Y-axis represent cell count while X-axis represent the mean fluorescent, where I = Control, $2=$ Buffer, $3=$ VIP $(\mathrm{I} \mu \mathrm{M}), 4=\mathrm{FKN}(\mathrm{I} \mathrm{ng} / \mathrm{ml}), 5=\mathrm{VIP}(\mathrm{I} \mu \mathrm{M})+\mathrm{FKN}(\mathrm{I} 0 \mathrm{ng} / \mathrm{ml})$. Histograms are one representative of 6 different experiments all showing similar results. (d) F-actin dynamics and cell shape changes induced by different stimulants. (A) Control-I 5 minutes stimulation (Buffer), (B) VIP I $\mu$ M- I5 minutes stimulation, (c) VIP I $\mu$ M-30 minutes stimulation, (D) FKN 10 ng/ml-I5 minutes stimulation (E) VIP I $\mu$ M-I5 minutes stimulation, cells were washed twice, and re-stimulated with FKN IOng/ml for 5 minutes. Images are from one representative of 6 independent experiments which all show similar images. 
The suboptimal dose of $10 \mathrm{ng} / \mathrm{ml} \mathrm{FKN} \mathrm{did} \mathrm{not} \mathrm{cause}$ significant increase of F-actin contents or shape changes, but reorganized the intracellular F-actin homogeneously in a clump-like manner within the spherical cell (compare FACS results 1 and 2 with 4 in Figure 1c and confocal images A with D in Figure 1d). However, the same suboptimal dose caused a rapid increase in the F-actin contents and shape changes after the cells were primed by a physiological dose of VIP (compare FACS results 1 and 2 with 5 in Figure 1c and confocal images A with $\mathrm{E}$ in figure 1d). VIP alone did not cause any increase in the F-actin contents or shape changes but caused a characteristic peripheral, membrane bound intracellular reorganization of F-actin in the spherical cells in a time-dependent manner (compare FACS results of 1 and 2 with 3 in Figure 1c and confocal images $A$ and $B$ with $C$ in Figure 1d).

The crosstalk between different agonist stimulants of cell receptors may indicate a novel role for F-actin physical reorganization independent from shape changes and increase in its contents in mast cells migration. In this context it is possible that high and low affinity receptors of chemokines (FKN) on the surface of mast cells are differently linked to F-actin changes, ie, the optimal dose will cause a rapid increase in F-actin contents that is associated with the rapid intracellular reorganization and shape changes through PKC epsilon and delta (El-Shazly et al 2006), while the suboptimal dose will only reorganize the F-actin homogeneously in a clusterlike manner as shown in this study. On the other hand, chemotaxis primers of mast cells such as VIP may induce a calcium-independent change in the signal transduction towards tyrosine kinases and p38 MAPK as we reported elsewhere (El-Shazly et al 2006) that is linked to peripheral reorganization of the F-actin in the spherical cell in a membrane-bound manner without increasing the F-actin contents or causing shape changes as demonstrated in this study. This is further supported by previous reports linking the involvement of p38-MAPK with the physical reorganization of F-actin (Kutsuna et al 2004; Kobayashi et al 2006; Ju et al 2007; Kim et al 2008).

Taken collectively, the results presented herein may identify a significant role for the unique pattern of the $\mathrm{Ca}^{2+}$-independent $\mathrm{F}$-actin biophysical dynamics in human mast cells migratory response to crosstalk between mediators and cell type at the inflammatory site. If so, then antagonists at the level of cell receptors may provide a therapeutic target for F-actin in treating mast cells in allergic inflammation.

\section{Acknowledgments}

The author wishes to acknowledge Prof. Tunon De Lara J. M. and Dr Patrick Berger for their critical discussion as coauthors in related previously published work and for the materials used. Also a special thank is due to Prof. Marthan R. for the laboratory facilities at the Laboratoire de Physiologie Cellulaire Respiratoire, Universite Victor Segalen Bordeaux 2-France. The author reports no conflicts of interest in this work.

\section{References}

Bacon KB, Szabo MC, Yssel H, et al. 1996. RANTES induces tyrosine kinase activity of stably complexed p125 FAK ands ZAP-70 in human T cells. J Exp Med, 184:873-82.

Baraniuk JN, Okayama M, Lundgren JD, et al. 1990. Vasoactive intestinal peptide in human nasal mucosa. J Clin Invest, 86:825-31.

Berger P, Tunon-de-Lara JM, Savineau JP, et al. 2001. Tryptase-induced PAR-2-mediated $\mathrm{Ca}^{2}{ }^{+}$signaling in human airway smooth muscle cells. J Appl Physiol, 919:95-1003.

Bokoch GM. 1995. Chemoattractant signaling and leukocyte activation. Blood, 86:1649-60.

Bonnet S, Dumas-de-La-roque E, Bégueret H, et al. 2003. Dehydroepiandrosterone (DHEA) prevents and reverses chronic hypoxic pulmonary hypertension. Proc Natl Acad Sci US A, 100:9488-93.

Brightling CE, Ammit AJ, Kaur D, et al. 2005. The CXCL10/CXCR3 axis mediates human lung mast cell migration to asthmatic airway smooth muscle. Am J Respir Crit Care Med, 171:1103-8.

Butterfield JH, Weiler D, Dewald G, et al. 1988. Establishment of an immature mast cell line from a patient with mast cell leukemia. Leuk Res, 12:345-55.

Delgado M, De la Fuente M, Martinez C, et al. 1995. Pituitary abenylate cyclase-activating polypeptides inhibit the mobility of murine thymocytes and splenic lymphocytes: Comparison with and implication of cAMP. J Neuro Immunol, 62:137-46.

Downey GP. 1994. Mechanisms of leukocyte motility and chemotaxis. Curr Opin Immunol, 6:113-24.

El-Shazly A, Berger P, Girodet PO, et al. 2006. Fraktalkine produced by airway smooth muscle cells contributes to mast cell recruitment in asthma. J Immunol, 176:1860-8.

El-Shazly A, Masuyama K, Eura M, et al. 1996. Immunoregulatory role of substance $\mathrm{P}$ in human eosinophil migratory function. Immunol Invest, 25:191-201.

El-Shazly A, Masuyama K, Ishikawa T. 1997. Mechanisms involved in activation of human eosinophil exocytosis by substance P: An in vitro model of sensory neuroimmunomodulation. Immunol Invest, 26:615-29.

El-Shazly A, Masuyanma K, Tsunoda N, et al. 2000. Non-specific activation of human eosinophil functional responses by vasoactive intestinal peptide. Allergology Int, 49:19-26.

Ghatei MA, Sheppard M, O'Shaughnessy DJ, et al. 1982. Regulatory peptides in the mammalian respiratory tract. Endocrinology, 111:1248-54.

Jackson NE, Wang HW, Tedla N, et al. 2005. IL-15 induces mast cell migration via a pertussis toxin-sensitive receptor. Eur J Immunol, 35:2376-85.

Ju Y, Wang T, Li Y, et al. 2007. Coxsackievirus B3 affects endothelial tight junctions: possible relationship to ZO-1 and F-actin, as well as p38 MAPK activity. Cell Biol Int, 31:1207-13.

Kim SJ, Jeong HJ, Park RK. 2007. The regulatory effect of SC-236 (4-[5-(4chlorophenyl)-3-(trifluoromethyl)-1-pyrazol-1-1]benzenesulfonamide) on stem cell factor induced migration of mast cells. Toxicol Appl Pharmacol, 220:138-45. 
Kim MS, Kewalramani G, Puthanveetil P, et al. 2008. Acute diabetes moderates trafficking of cardiac lipoprotein lipase through p38 mitogenactivatid protein kinase-dependent actin cytoskeleton organization. Diabetes, 57:64-76.

Knall C, Worthen GS, Johnson GL. 1997. Interleukin 8-stimulated phosphatidylinositol-3-kinase activity regulates the migration of human neutrophils independent of ectracellular signal-regulated kinase and p38 mitogenactivated protein kinases. Proc Natl Acad Sci US A, 94:3052-7.

Kobayashi M, Nishita M, Mishima T, et al. 2006. MAPKAPK-2-mediated LIM-kinase activation is critical for VEGF-induced actin remodeling and cell migration. EMBO J, 25:713-26.

Kutsuna H, Suzuki K, Kamata N, et al. 2004. Actin reorganization and morphological changes in human neutrophils stimulated by TNF, GM-CSF, and G-CSF: the role of MAP kinases. Am J Physiol Cell Physiol, 286:55-64.

Mosimann BL, White MV, Hohman RJ et al. 1993. Substance P, calcitonin gene-related peptide, and vasoactive intestinal peptide increase in nasal secretions after allergen challenge in atopic patients. J Allegy Clin Immunol, 92:95-104.

Numao T, Agrawal DK. 1992. Neuropeptides modulate human eosinophil chemotaxis. J Immunol, 149:3309-15.

Palmer JBD, Cuss FMC, Barnes PJ. 1986. VIP and PHM and their role in nonadrenergic inhibitory responses in isolated human airway. $J \mathrm{Appl}$ Physiol, 61:1322-8.
Peatfield AC, Barnes PJ, Bratcher C, et al. 1983. Vasoactive intestinal peptide stimulates tracheal submucosal gland secretion in ferret. Am Rev Respir Dis, 128:89-93.

Rivera J, Olivera A. 2007. Src family kinases and lipid mediators in control of allergic inflammation. Immunol Rev, 217:255-68.

Said SI. 1982. Vasoactive peptides in the lung, with special reference to vasoactive intestinal peptide. Exp Lung Res, 3:343-8.

Samayawardhena LA, Hu J, Stein PL, et al. 2006. Fyn kinase acts upstream of Shp2 and p38 mitogen-activated protein kinase to promote chemotaxis of mast cells towards stem cell factor. Cell Signal, 18:1447-54.

Samayawardhena LA, Kapur R, Craig AW. 2007. Involvement of Fyn kinase in Kit and integrin-mediated Rac activation, cytoskeletal reorganization, and chemotaxis of mast cells. Blood, 109:3679-86.

Stjarne P, Lacroix JS, Anggard A, et al. 1991. Compartment analysis of vascular effects of neuropeptides and capsaicin in pig nasal mucosa. Acta Physiol Scand, 141:335-42.

Sutcliffe A, Kaur D, Page S, et al. 2006. Mast cell migration to Th2 stimulated airway smooth muscle from asthmatics. Thorax, 61:657-62.

Tsang CM, Wong CK, Ip WK, et al. 2005. Synergistic effect of SCF and TNF-alpha on the up-regulation of cell-surface expression of ICAM-1 on human leukemic mast cell line (HMC)-1 cells. J Leukoc Biol, 78:239-47. 
